\title{
Utilisation of redundant time on trauma list for carpal tunnel decompression
}

\author{
B Theruvil, R K Choudhary, V Kapoor, D G Hargreaves, D J Warwick
}

Postgrad Med J 2005;81:613-614. doi: 10.1136/pgmi.2004.029769

This audit reviewed the trauma theatre time utilisation during April 2000 to March 2001. Instead of a scheduled 830 am start, first patient was on the table by only 940 am because of various reasons. To use this redundant time carpal tunnel release was started under local anaesthesia, as first case. On re-auditing, it was found that the patient for carpal tunnel release was on the table at $844 \mathrm{am}$. The first trauma case was on the table at $946 \mathrm{am}$. This simple idea has helped in the performing of an additional case every day with a delay to the trauma list of only six minutes $(p<0.05)$

$\mathrm{E}$ fficient utilisation of the trauma list is an important aspect of patient care in the NHS. We found that there was often a delay in the starting time of the first case on the trauma list because of various reasons. We introduced the novel idea of performing carpal tunnel release (CTR) as the first case of each trauma list, to make use of the redundant time. We report our experience of performing carpal tunnel decompression on the trauma list and the impact this had on the operating list.

\section{METHODS}

Southampton General Hospital is a tertiary referral centre. The trauma and orthopaedics unit has bed strength of 160 . Around 1600 trauma operations are performed yearly. There is a dedicated trauma list on weekdays, scheduled to start at 8 $30 \mathrm{am}$ and finish at $5 \mathrm{pm}$.

Trauma theatre time utilisation was audited from April 2000 to March 2001. For the purpose of the study, "start" was defined as the moment of skin incision and "finish" when the patient was moved out of the operating table. A "delay" was defined as any event more that 15 minutes later than expected.

In May 2002, we started doing CTR as the first case on the trauma theatre lists. The trauma theatre time utilisation was re-audited after the introduction of carpal tunnel release.

\section{RESULTS}

\section{Initial audit}

Of the 141 trauma lists audited, the mean start time was found to be 940 am despite a scheduled start time of $830 \mathrm{am}$. The main reasons for the delay were the time required for the anaesthetist to see the patient $(58 \%)$ and the other staff to set up the necessary equipments $(28 \%)$. Surgeons were implicated in $14 \%$ of the delays.

\section{Re-audit}

The trauma theatre time utilisation was re-audited after the introduction of the CTR. We studied 140 lists and found that the start time for CTR was $844 \mathrm{am}$ (mean). The start time of the first trauma case was 946 am (mean). After we started performing CTR as the first case, we were able to reduce the start delay from 70 minutes to 14 minutes. Therefore despite performing an additional surgery on the list there was a delay of only six minutes $(p<0.05)$ to the start of first trauma case.

CTR had to be cancelled on three occasions in the one year period we audited, once because of medical reasons, and twice as the theatre was being used to perform emergency operations in patients with multiple injuries.

\section{DISCUSSION}

Operating sessions are an expensive and limited resource. Throughput in operating theatre is often used as an index of surgeon's performance. ${ }^{1}$ In the first audit our aim was to determine the use of trauma list time and the causes for delayed starts.

CTR is among one of the most commonly performed procedures by orthopaedic surgeons. By performing CTR as the first case, we felt, we could tackle the common three causes of delays to the trauma list. This is a short procedure that can be performed by a junior grade surgeon giving time for the senior surgeon to complete post on-call ward rounds. As this is commonly performed under local anaesthetic, the presence of an anaesthetist is not required. ${ }^{2}$ Thereby the anaesthetist has sufficient time for assessment of patients on the trauma list. This also gives the theatre staff ample time for preparing complex instrumentations, if required, for the first trauma case.

After an extensive literature search we could only find one study where the orthopaedic theatre times were studied. Ricketts et al found that $60 \%$ of elective theatre time was used for operating and $21 \%$ for turnover. ${ }^{3}$ No useful activity occurred during the remaining $19 \%$ of the time. There was an average start delay of 26.5 minutes. In contrast with the study by Ricketts et al, we audited the timing of trauma lists that are well known for their unpredictability.

Ineffective use of expensive capital resources, such as theatre time, should not be acceptable to those responsible for the provision of health care. Since this audit, a third of carpal tunnel decompressions done in our hospital are now performed on trauma lists. This has also had a huge impact on reducing the waiting times required for CTR in our hospital. Better organisation and predictability of the start of the trauma list has improved the staff morale and working practices.

In the NHS, where pressures on waiting lists keep growing, we feel that simple and effective ideas like this can help make a big difference.

\section{Authors' affiliations}

B Theruvil, R K Choudhary, V Kapoor, D G Hargreaves, D J Warwick, Department of Orthopaedics, Southampton University Hospital,

Southampton, UK

Funding: none. 
Conflicts of interest: none.

Correspondence to: Mr D J Warwick, Department of Orthopaedics, Southampton University Hospital, Southampton SO16 6UY, UK; davidwarwick@handsurgery.co.uk

Submitted 19 October 2004

Accepted 22 November 2004

\section{REFERENCES}

1 Opit L, Collins RE, Campbell G. Use of operating theatres: the effects of casemix and training in general surgery. Ann R Coll Surg Engl 1991;73:389-92.

2 Baguneid MS, Sochart DH, Dunlop D, et al. Carpal tunnel decompression under local anaesthetic and tourniquet control. J Hand Surg [Br] 1997;22:322-4.

3 Ricketts D, Hartley J, Patterson M, et al. An orthopaedic theatre timings survey. Ann R Coll Surg Engl 1994;76:200-4.

\section{Clinical Evidence-Call for contributors}

Clinical Evidence is a regularly updated evidence-based journal available worldwide both as a paper version and on the internet. Clinical Evidence needs to recruit a number of new contributors. Contributors are healthcare professionals or epidemiologists with experience in evidence-based medicine and the ability to write in a concise and structured way.

Areas for which we are currently seeking authors:

- Child health: nocturnal enuresis

- Eye disorders: bacterial conjunctivitis

- Male health: prostate cancer (metastatic)

- Women's health: pre-menstrual syndrome; pyelonephritis in non-pregnant women

However, we are always looking for others, so do not let this list discourage you.

Being a contributor involves:

- Selecting from a validated, screened search (performed by in-house Information Specialists) epidemiologically sound studies for inclusion.

- Documenting your decisions about which studies to include on an inclusion and exclusion form, which we keep on file.

- Writing the text to a highly structured template (about 1500-3000 words), using evidence from the final studies chosen, within 8-10 weeks of receiving the literature search.

- Working with Clinical Evidence editors to ensure that the final text meets epidemiological and style standards.

- Updating the text every six months using any new, sound evidence that becomes available. The Clinical Evidence in-house team will conduct the searches for contributors; your task is simply to filter out high quality studies and incorporate them in the existing text.

- To expand the topic to include a new question about once every 12-18 months.

If you would like to become a contributor for Clinical Evidence or require more information about what this involves please send your contact details and a copy of your CV, clearly stating the clinical area you are interested in, to Klara Brunnhuber (kbrunnhuber@ bmigroup.com).

\section{Call for peer reviewers}

Clinical Evidence also needs to recruit a number of new peer reviewers specifically with an interest in the clinical areas stated above, and also others related to general practice. Peer reviewers are healthcare professionals or epidemiologists with experience in evidence-based medicine. As a peer reviewer you would be asked for your views on the clinical relevance, validity, and accessibility of specific topics within the journal, and their usefulness to the intended audience (international generalists and healthcare professionals, possibly with limited statistical knowledge). Topics are usually 1500-3000 words in length and we would ask you to review between $2-5$ topics per year. The peer review process takes place throughout the year, and our turnaround time for each review is ideally 10-14 days.

If you are interested in becoming a peer reviewer for Clinical Evidence, please complete the peer review questionnaire at www.clinicalevidence.com or contact Klara Brunnhuber (kbrunnhuber@bmigroup.com). 